\title{
Effect of phenylephrine vs. ephedrine on frontal lobe oxygenation during caesarean section with spinal anesthesia: an open label randomized controlled trial
}

\author{
Visti T. Foss ${ }^{1 *}$, Robin Christensen ${ }^{2}$, Kim Z. Rokamp ${ }^{1}$, Peter Nissen ${ }^{3}$, Niels H. Secher ${ }^{3}$ and \\ Henning B. Nielsen ${ }^{3}$ \\ ' Department of Anaesthesia, Næstved Hospital, Næstved, Denmark \\ ${ }^{2}$ Musculoskeletal Statistics Unit, Department of Rheumatology, The Parker Institute, Frederiksberg Hospital, University of Copenhagen, Copenhagen, Denmark \\ ${ }^{3}$ Department of Anaesthesia, Rigshospitalet, University of Copenhagen, Copenhagen, Denmark
}

Edited by:

Patrice Brassard, Laval University,

Canada

Reviewed by:

Ashraf Habib, Duke University, USA

Samuel J. E. Lucas, University of

Birmingham, UK

\section{*Correspondence:}

Visti T. Foss, Department of

Anaesthesia, Næstved Hospital,

Ringstedgade 61, 4700 Næstved,

Denmark

e-mail: vistifoss@gmail.com
Background: During caesarean section spinal anesthesia may provoke maternal hypotension that we prevent by administration of phenylephrine and/or ephedrine. Phenylephrine is however reported to reduce the near infrared spectroscopy-determined frontal lobe oxygenation $\left(\mathrm{ScO}_{2}\right)$ but whether that is the case for patients exposed to spinal anesthesia is not known.

Objectives: To evaluate the impact of phenylephrine vs. ephedrine on $\mathrm{ScO}_{2}$ during caesarean section with spinal anesthesia in a single center, open-label parallel-group study with balanced randomization of 24 women (1:1). Secondary aims were to compare the effect of the two drugs on maternal hemodynamics and fetal heart rate.

Intervention: Ephedrine (0.8-3.3 mg/min) vs. phenylephrine infusion $(0.02-0.07 \mathrm{mg} / \mathrm{min})$.

Results: For the duration of surgery, administration of ephedrine maintained $\mathrm{ScO}_{2}$ (compared to baseline $+2.1 \pm 2.8 \%$; mean $\pm \mathrm{SE}$, while phenylephrine reduced $\mathrm{ScO}_{2}$ $(-8.6 \pm 2.8 \% ; p=0.005)$ with a $10.7 \%$ difference in $\mathrm{ScO}_{2}$ between groups $(p=0.0106)$. Also maternal heart rate was maintained with ephedrine $(+3 \pm 3 \mathrm{bpm})$ but decreased with phenylephrine $(-11 \pm 3 \mathrm{bpm})$; difference $14 \mathrm{bpm}(p=0.0053)$, but no significant difference in mean arterial pressure $(p=0.1904)$ or $\mathrm{CO}(p=0.0683)$ was observed between groups. The two drugs also elicited an equal increase in fetal heart rate (by $19 \pm 3 \mathrm{vs} .18 \pm 3 \mathrm{bpm}$; $p=0.744)$.

Conclusion: In the choice between phenylephrine and ephedrine for maintenance of blood pressure during caesarean section with spinal anesthesia, ephedrine maintains frontal lobe oxygenation and maternal heart rate with a similar increase in fetal heart rate as elicited by phenylephrine.

Trial registration: Clinical trials NCT 01509521 and EudraCT 200100610335.

\section{INTRODUCTION}

Spinal anesthesia is used for caesarean section although it is commonly associated with hypotension. In addition to tilting patient to the left and providing i.v. fluids, we use ephedrine and/or phenylephrine to prevent or correct hypotension that could result in, e.g., dizziness, nausea, and vomiting and also hinder adequate perfusion of the child (Berlac and Rasmussen, 2005; Cyna et al., 2006; Saravanan et al., 2006; Ngan Kee et al., 2008a).

The effect of ephedrine and phenylephrine on maternal and fetal hemodynamics has been investigated extensively (Mercier et al., 2001; Saravanan et al., 2006; Langesaeter et al., 2008; Ngan Kee et al., 2008a) There seems to be no difference between the two drugs in regards to preventing hypotension following spinal anesthesia for caesarean section (Cyna et al., 2006) However, fetal tachycardia appears to be more frequent with the use of ephedrine, or combined ephedrine and phenylephrine than with the use of phenylephrine (Wang et al., 2011) Furthermore, the effect of phenylephrine on fetal acid base status seems to be more favorable than manifested with the use of ephedrine (Vesser et al., 2012).

On the other hand, near infrared spectroscopy (NIRS) determined cerebral (frontal lobe) oxygenation $\left(\mathrm{ScO}_{2}\right)$ decreases when hypotension is supported by phenylephrine (Nissen et al., 2009a, 2010; Ogoh et al., 2011; Meng et al., 2011a) while it is maintained with the use of ephedrine (Nissen et al., 2010; Meng et al., 2011a; Ogoh et al., 2011) We investigated how phenylephrine and ephedrine influence $\mathrm{ScO}_{2}$ when used to prevent maternal hypotension during caesarean section performed under spinal anesthesia where phenylephrine may hinder accumulation of blood in the blocked area of the body and thereby support 
cardiac output (CO)(Cannesson et al., 2012) and in turn $\mathrm{ScO}_{2}$. Thus, we hypothesized that administration of both ephedrine and phenylephrine would maintain $\mathrm{ScO}_{2}$ in patients undergoing caesarean section with spinal anesthesia since an increase in vascular tone can enhance venous return and thereby support cardiac preload and CO during hypovolemia as demonstrated in anesthetized pigs (Cannesson et al., 2012) In this randomized clinical trial the primary outcome was to evaluate the $\mathrm{ScO}_{2}$ response to administration of ephedrine vs. phenylephrine. Secondary aims were to evaluate changes in maternal hemodynamics and in fetal heart rate. Umbilical cord blood gas variables were also determined.

\section{METHODS}

For this single center, open label, parallel-group study with balanced randomization (1:1), written informed consent was obtained from healthy women undergoing elective caesarean section during spinal anesthesia after approval by the local ethics committee (SJ-271) and the Danish medicine agency (NCT 01509521; EudraCT 2001006103 35). The Good Clinical Practice (GCP) unit at the University of Copenhagen monitored the trial conducted from April 2012 to July 2012 at Næstved Hospital. Eligible participants were older than 18 years in ASA group I or II, $160-180 \mathrm{~cm}$ and with a single pregnancy. Patients with either preeclampsia, non-singleton pregnancy, HELLP-syndrome (hemolysis, elevated liver enzyme, low platelet count), elevated serum bilirubin, or reported allergy to ephedrine or phenylephrine were excluded from the study.

\section{PREPARATION}

Upon arrival to the operating theater, the patient was provided with $500 \mathrm{~mL}$ isotonic saline, tilted $15^{\circ}$ to the left and nasal supplementation of oxygen $(2 \mathrm{~L} / \mathrm{min})$ was established. A cuff was applied to the third finger of the left hand and heart rate (HR), systolic (SBP), diastolic (DBP) and mean arterial (MAP) blood pressures were determined by Nexfin (BMEYE, The Netherlands, Amsterdam). Thus stroke volume (SV) was determined from the pressure curve using Modelflow (Bogert and van Lieshout, 2005) that takes sex, age, and weight into account. CO (SV times HR) and total peripheral resistance (TPR; MAP divided by CO) were calculated. Nexfin data were obtained on a beat to beat basis and averaged over $15 \mathrm{~s}$ every $2.5 \mathrm{~min}$. Fetal HR was obtained by Doppler (Sonicaid Dopplers, Luton, Huntleigh, UK) and averaged over $15 \mathrm{~s}$ from before spinal anesthesia (baseline) and after spinal anesthesia (2.5-5 min), during surgery (7.5-17.5 min), and after delivery (13-28 $\mathrm{min})$.

\section{SPINAL ANESTHESIA}

With $2.4 \mathrm{~mL}$ bupivacaine $0.5 \%$ ( $12 \mathrm{mg}$ ) and $10 \mu \mathrm{g}$ fentanyl spinal anesthesia was established using a 27 or $25 \mathrm{G}$ pencil point needle at the L2-L3 or L3-L4 intervertebral space. Spinal anesthesia was administered in the right lateral position in 21 patients and in three patients spinal anesthesia was provided in a seated position. Surgery started when the sensory block included the T5 dermatome as indicated by the loss of sensation to application of cold to the skin.

\section{FRONTAL LOBE OXYGENATION}

$\mathrm{ScO}_{2}$ was monitored by NIRS (INVOS 3100 Cerebral Oxymeter, Somanetics, Troy, USA). Optodes were placed on both sides of the forehead immediately below the hairline and secured with a headband that also served to seal ambient light. The NIRSdetermined mean $\mathrm{ScO}_{2}$ is based on optodes that emit and detect near-infrared light at two wavelengths $(730$ and $810 \mathrm{~nm})$ and $\mathrm{ScO}_{2}$ is calculated as the ratio between oxyhemoglobin and total hemoglobin. The signal detector closest to the light source $(3 \mathrm{~cm})$ is considered the "shallow detector" and used to attenuate influence from superficial tissue, while the detector $4 \mathrm{~cm}$ from the light source is considered to detect light from "deep tissue." The distance between the source and detectors is considered sufficient for light to reach the brain (Choi et al., 2004) Thus it was assumed that values are accounted for predominantly by hemoglobin in the frontal lobe cortex, although a contribution from the skin is acknowledged (Davie and Grocott, 2012).

\section{INTERVENTIONS AND RANDOMIZATION}

The patients were allocated randomly into two groups (ephedrine or phenylephrine) of 12 using sequentially numbered, opaque, sealed envelopes prepared by an individual not involved in the study. Dose equivalence between phenylephrine $(0.1 \mathrm{mg} / \mathrm{mL})$ and ephedrine $(5 \mathrm{mg} / \mathrm{mL})$ was chosen in according to previous trials and recommendations (Saravanan et al., 2006; Ngan Kee et al., 2008b; Das et al., 2011).

After spinal anesthesia, the infusion was started $(20 \mathrm{ml} / \mathrm{h}$; $1.6 \mathrm{mg} / \mathrm{min}$ for ephedrine and $0.03 \mathrm{mg} / \mathrm{min}$ for phenylephrine) and adjusted to maintain SBP. If SBP increased from baseline by $10-20 \%$, the infusion was reduced to $10 \mathrm{~mL} / \mathrm{h}$ and paused if SBP increased more than 20\%. Conversely, if SBP decreased by $10-20 \%$, the infusion was increased to $40 \mathrm{~mL} / \mathrm{h}$. A bolus of either $10 \mathrm{mg}$ ephedrine or $0.2 \mathrm{mg}$ phenylephrine was to be administered if SBP decreased by more than $20 \%$, or if the patient complained of symptoms of hypotension (dizziness, vomiting, faintness, nausea). At delivery the infusion was reduced to $10 \mathrm{~mL} / \mathrm{h}$ and terminated $5-15 \mathrm{~min}$ thereafter. Data collected included Apgar score, and umbilical arterial and venous blood gas variables from a double-clamped cord segment. Further, data pertaining to the duration of surgery, volume of saline administered and the vasopressor dosages used are mentioned.

\section{OUTCOME MEASURES}

The primary outcome is expressed as the percentage $\mathrm{ScO}_{2}$ change from baseline, with baseline defined as rest prior to spinal anesthesia (time $0 \mathrm{~min}$ ). The secondary outcomes variables (maternal hemodynamics and fetal heart rate) were also expressed as the change from baseline and all observations were continued until the end of surgery.

\section{STATISTICAL ANALYSIS}

Power calculations based on former studies (Nissen et al., 2010; Kim et al., 2000) revealed that in order to detect a statistically significant difference between means of 57 and $67 \%$ in $\mathrm{ScO}_{2}$, assuming a common standard deviation of $7 \%$, a sample size of $n=9$ per group was required to obtain a power of a least $0.8(\beta=20 \%$; two-tailed $\alpha=5 \%)$. To compensate for 
potential dropouts and missing data (25\%) the sample size was increased to 12 participants per group. Data analyses were according to a pre-established plan using SAS software (v. 9.2; SAS Institute Inc., Cary, NC, USA). Descriptive statistics and tests are reported in accordance with the "Enhancing the QUAlity and Transparency Of health Research" (EQUATOR) network: the CONSORT Statement (Schulz et al., 2010). In order to evaluate data distribution of the outcome and statistical models, inspection was used to suggest whether the assumption of normality was reasonable. The PROC UNIVARIATE statement was used to summarize descriptive data. If the assumption of normality was not reasonable, we analyzed the data with the nonparametric Wilcoxon Rank Sum test using PROC NPAR1WAY; and the median difference was reported. The 95\% confidence limit was estimated from an approximated standard error, based on the Wilcoxon $p$-value from a Wald- $Z$-test.

To analyse the longitudinal element of the study objectives, a linear approach was used for repeated measurements, using the procedure PROC MIXED based on restricted maximum likelihood (REML) estimates of the variables (Littell et al., 2000). The factor Subject was applied as a random effect factor. Assessment of the treatment and time effects tested possible interaction and both treatment and time were included as systematic factors using the baseline value as co-variate to reduce random variation and increase power. Unless stated otherwise, results are expressed as the difference between the group means and 95\% CI with the associated $p$-values, based on the mixed linear model. The average change from the baseline during the study in each group was analyzed based on the mixed model with only the main effects of group and time without taking interaction into account. All comparisons were two tailed and $p<0.05$ was considered statistically significant.

\section{RESULTS}

\section{PATIENTS}

Written informed consent to participate in the study was obtained from 33 patients; 24 of whom were subsequently randomized (Figure 1) and the randomized patients had a body mass index of 30.1 (5.4) mean (SD), range $21.6-41.6 \mathrm{~kg} / \mathrm{m}^{2}$ (Table 1 ).

\section{FRONTAL LOBE OXYGENATION}

In patients allocated to administration of phenylephrine $\mathrm{ScO}_{2}$ decreased by $-8.6 \pm 2.8 \%$ while in patients randomized to infusion of ephedrine, $\mathrm{ScO}_{2}$ was not affected $(+2.1 \pm 2.8 \%)$. Comparing the values determined in the two groups, the difference in $\mathrm{ScO}_{2}$ was 10.7\% (95\% CI 2.8-18.7\%, $p=0.0106$ : Table 2, Figure 2). Whereas $\mathrm{ScO}_{2}$ was reduced from baseline in the phenylephrine group $(p=0.005)$, this was not the case with the administration of ephedrine $(p=0.4657)$.

\section{CARDIOVASCULAR EFFECTS}

Phenylephrine $(-14 \pm 3 \mathrm{mmHg})$ and ephedrine $(-20 \pm$ $3 \mathrm{mmHg}$ ) were equally effective in maintaining MAP (Figure 3) with a group mean difference of $6 \mathrm{mmHg}(95 \% \mathrm{CI}-15$ to 3 , $p=0.1904)$. Similar results were obtained for DBP and SBP (Table 2). The maternal HR was maintained with ephedrine $(+3 \pm 3 \mathrm{bpm})$ but decreased with phenylephrine $(-11 \pm 3 \mathrm{bpm})$; difference 14 (95\% CI 5-23, $p=0.0053)$ bpm. SV appeared to increase both with phenylephrine $(9.7 \pm 4.8 \mathrm{ml})$ and with ephedrine $(4.4 \pm 5.0 \mathrm{ml})$, but this difference was not significant: $-5.3 \mathrm{ml}(95 \% \mathrm{CI}-18.9$ to $8.3, p=0.4299)$. In the ephedrine group CO increased by $0.9 \pm 0.4 \mathrm{l} / \mathrm{min}$, while in the phenylephrine group $\mathrm{CO}$ was stable $(-0.1 \pm 0.4 \mathrm{l} / \mathrm{min})$; $95 \%$ CI -0.08 to $2.02, p=0.0683$ ). There was a tendency for TPR to be lower in the ephedrine group compared with the phenylephrine group $(-232 \pm 42$ vs. $-129 \pm 41)$ dyn s $\mathrm{cm}^{-5}$ $(p=0.0684)$.

\section{FETAL VARIABLES}

The difference in fetal heart rate between the ephedrine and phenylephrine group was $1 \mathrm{bpm}(95 \% \mathrm{CI}-6$ to $9, p=0.7441)$; for ephedrine $+19 \pm 3$ vs. $+18 \pm 3 \mathrm{bpm}$ for phenylephrine (Table 2, Figure 4). When compared to baseline both ephedrine $(p<0.005)$ and phenylephrine $(p<0.005)$ increased fetal heart rate. All Apgar scores were $=8$ one minute after delivery and increased to 10 after $5 \mathrm{~min}$ in both groups. There was a difference $(p=0.0223)$ in regard to the umbilical venous base excess: -1.0 ( $95 \%$ CI -0.86 to -0.14$) \mathrm{mM}$ and arterial umbilical lactate was higher in the ephedrine than in the phenylephrine group: 0.50 (95\% CI 0.09-0.91) mM, $p=0.017$, while no differences were observed in any of the other umbilical cord blood variables assessed (Table 3).

\section{OPERATIVE RESULTS}

The time between intra-thecal injection and start of surgery [difference 0.0 (95\% CI -2.8 to 2.8$) \mathrm{min}, p=0.9976)]$ and between intra-thecal injection and delivery [difference 0.2 (95\% CI 0.2 to 3.2) $\min , p=0.9106)$ ] were similar for the ephedrine and the phenylephrine groups (Table 4). The amount of i.v. saline was also equal between the two groups: $63 \mathrm{ml}$ (95\% CI -259 to 134, $p=0.0515)$ and there was no difference in the blood loss $(100 \mathrm{ml}$ ( $95 \%$ CI of difference -275 to 475 ), $p=0.601$ ).

\section{VASOPRESSOR DOSE}

The ephedrine dose per minute was $1.7 \mathrm{mg}$ (1.3-2) range 0.7$5.9 \mathrm{mg}$ and of phenylephrine $1.38 \mathrm{mg}(0.91-1.55)$ range $0.57-$ $1.82 \mathrm{mg}$. No patient was treated with both phenylephrine and ephedrine.

Further monitoring (not reported) included pulse oximetry, ECG, non-invasive blood pressure on the right arm after initiation of saline administration and continued until the patient was transferred to the postoperative observation unit (no abnormal values were noted).

\section{DISCUSSION}

The present study confirmed that phenylephrine and ephedrine are equally effective in maintaining MAP in patients undergoing caesarean section with spinal anesthesia. The new finding is that in patients undergoing spinal anesthesia, the use of the ephedrine, capable of activating both $\alpha$ and $\beta$ adrenergic receptors, preserves the near infrared-determined frontal lobe oxygenation $\left(\mathrm{ScO}_{2}\right)$ while $\mathrm{ScO}_{2}$ was reduced in patients allocated to administration of phenylephrine, a selective $\alpha$-adrenergic receptor agonist. We considered that women going through caesarean section during 


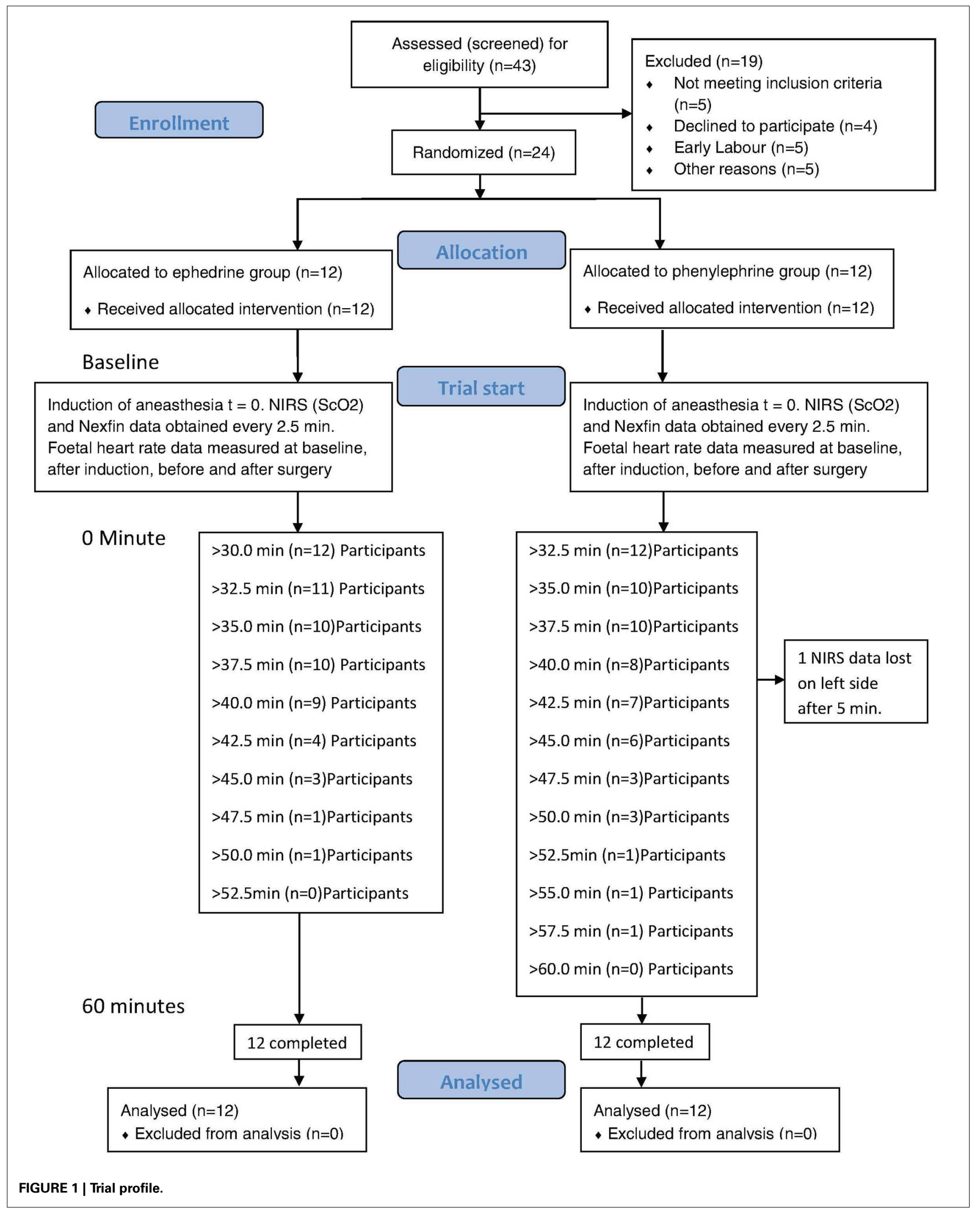


Table 1 | Patient characteristics, cardiovascular values, fetal heart rate, and frontal lobe oxygenation at baseline.

\begin{tabular}{|c|c|c|c|}
\hline & $\begin{array}{l}\text { Ephedrine } \\
\qquad N=12\end{array}$ & $\begin{array}{c}\text { Phenylephrine } \\
N=12\end{array}$ & $\begin{array}{c}\text { Total } \\
N=24\end{array}$ \\
\hline Age (years) & $30.8 \pm 5.5$ & $33.0 \pm 3.7$ & $31.9 \pm 4.7(21-39)$ \\
\hline Weight (kg) & $89 \pm 20$ & $81 \pm 8$ & $85 \pm 15.5(67-125)$ \\
\hline Body mass index $(\mathrm{kg} / \mathrm{m} 2)$ & $32.2 \pm 6.3$ & $28.1 \pm 3.2$ & $30.1 \pm 5.4(21.6-41.6)$ \\
\hline Mean arterial pressure $(\mathrm{mmHg})$ & $102 \pm 11$ & $101 \pm 12$ & $101 \pm 11(82-122)$ \\
\hline Heart rate (bpm) & $95 \pm 18$ & $89 \pm 21$ & $92 \pm 19(59-132)$ \\
\hline Stroke volume (ml) & $97 \pm 21$ & $105 \pm 20$ & $101 \pm 20(59-149)$ \\
\hline Cardiac output (L/min) & $8.9 \pm 1.1$ & $9.0 \pm 2.1$ & $8.9 \pm 1.6(5.7-13.2)$ \\
\hline Total peripheral resistance (dyn $\mathrm{s} \mathrm{cm}^{-5}$ ) & $933 \pm 162$ & $946 \pm 262$ & $940 \pm 213(570-1530)$ \\
\hline
\end{tabular}

Values are means $\pm S D$. (range: minimum and maximum).

Table 2 | Change in outcomes from baseline on average during $60 \mathrm{~min}$ trial period, in patients randomized to either ephedrine or phenylephrine.

\begin{tabular}{|c|c|c|c|c|}
\hline & $(n=12)$ Ephedrine & ( $n=12)$ Phenylephrine & Difference $(95 \% \mathrm{Cl})$ & $p$-Value \\
\hline Frontal lobe oxygenation (\%) & $2.1 \pm 2.8$ & $-8.6 \pm 2.8$ & $10.7(2.8-18.7)$ & 0.0106 \\
\hline Systolic pressure $(\mathrm{mmHg})$ & $-19 \pm 5$ & $-16 \pm 5$ & $-3(-17$ to 11$)$ & 0.6329 \\
\hline $\mathrm{MAP}(\mathrm{mmHg})$ & $-20 \pm 3$ & $-14 \pm 3$ & $-6(-15$ to 3$)$ & 0.1904 \\
\hline Heart rate (bpm) & $3 \pm 3$ & $-11 \pm 3$ & $14(5-23)$ & 0.0053 \\
\hline TPR (dyn s cm ${ }^{-5}$ ) & $-232 \pm 42$ & $-129 \pm 41$ & -103 (214 to 8) & 0.0684 \\
\hline Fetal heart rate (bpm) & $19 \pm 3$ & $18 \pm 3$ & $1(-6$ to 9$)$ & 0.7441 \\
\hline
\end{tabular}

Presented are the ephedrine and phenylephrine group with values in means \pm SE (standard error) and differences in mean changes (95\% CI). Values for frontal lobe oxygenation $\left(\mathrm{SCO}_{2}\right)$ are changes in percent.

spinal anesthesia might be hypovolemic because of compromised venous return and that phenylephrine therefore could support cardiac output and in turn cerebral oxygenation as expressed by $\mathrm{ScO}_{2}$. In contrast to our hypothesis, however, phenylephrine did not increase $\mathrm{CO}$ and maybe therefore reduced $\mathrm{ScO}_{2}$. In other word, with the established routine for maintaining the circulation during caesarean section during spinal anesthesia, $\mathrm{CO}$ in response to administration of phenylephrine indicated that the patients were maintained "normovolemic." Furthermore, only ephedrine maintained HR and the two drugs elicited an equal almost $20 \mathrm{bpm}$ increase in fetal heart rate.

Spinal anesthesia influences MAP because of sympathetic blockade and during caesarean section inferior caval compression may reduce venous return to the heart and thus CO (Cyna et al., 2006) During caesarean section hypotension is considered when maternal SBP decreases by $20-30 \%$ or decreases to less than 90-100 mmHg (Saravanan et al., 2006; Ngan Kee et al., 2008a) although we acknowledge that the lower limit of cerebral autoregulation has been challenged (Lucas et al., 2010; Tan, 2012). Thus, MAP did not fall to what is considered to be the lower limit of cerebral autoregulation (Paulson et al., 1990) and the patients were not expected to be exposed to cerebral hypoperfusion and a reduction in $\mathrm{ScO}_{2}$. However, administration of phenylephrine led to a $\sim 9 \%$ reduction in $\mathrm{ScO}_{2}$ (Figure 2, Table 2). A decrease in MAP to below $\sim 80 \mathrm{mmHg}$, as provoked for example during head-up tilt, reduces cerebral blood flow and $\mathrm{ScO}_{2}$ because of a reduced central blood volume and CO (Madsen et al., 1998) However, whether or not a balance exists between cerebral oxygen supply and demand during anesthesia-induced hypotension remains unknown (Meng et al., 2013).

A $10-15 \%$ reduction in $\mathrm{ScO}_{2}$ and a $50 \%$ reduction in middle cerebral artery mean flow velocity are associated with presyncopal symptoms (Kurihara et al., 2007) The 9\% reduction in $\mathrm{ScO}_{2}$ in response to administration of phenylephrine during spinal anesthesia for elective caesarean section approaches that level and could thus represent clinically important cerebral hypoperfusion (Hunt et al., 2006; Suzuki et al., 2008; Nissen et al., 2009b). On the other hand, the patients were awake and able to report hypotension-associated symptoms (nausea, vomiting or dizziness), but no complaints were expressed regardless 


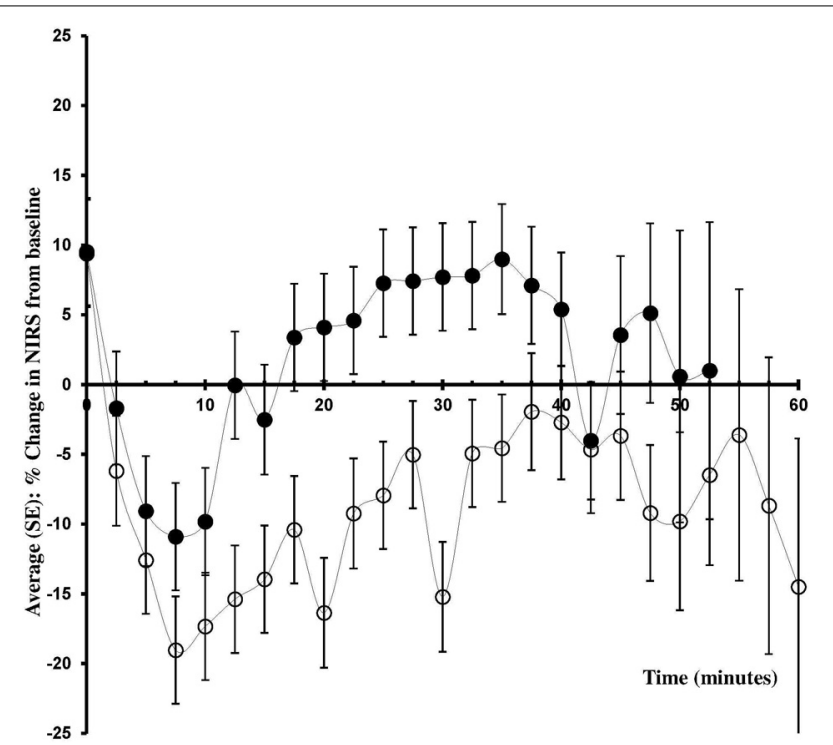

FIGURE 2 | Change in $\mathbf{S c O}_{\mathbf{2}}$ from baseline. Changes in frontal lobe oxygenation ( $\mathrm{ScO} 2$; \% from baseline) during caesarean section with spinal anesthesia. Patients received either phenylephrine ( $n=12$; open circles) or ephedrine ( $n=12$; black circles).

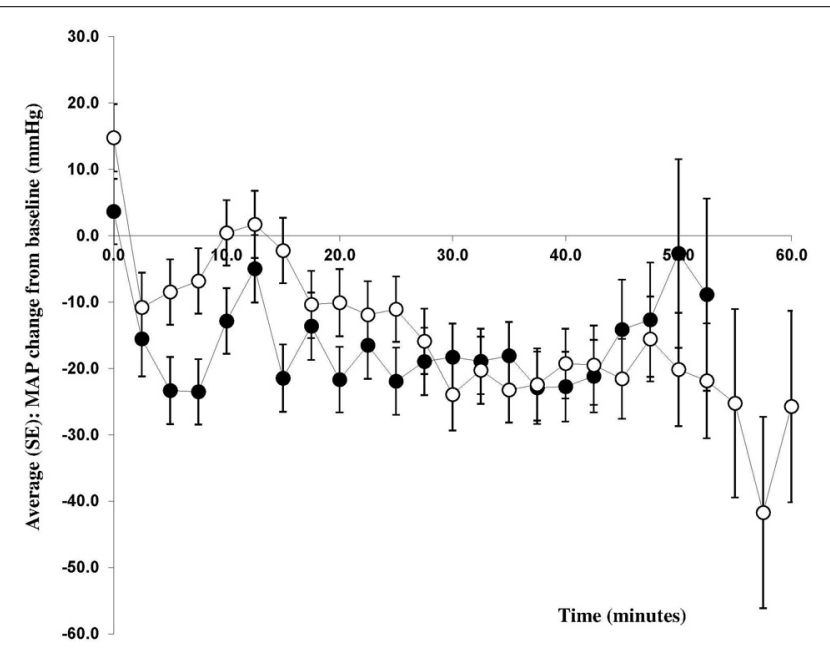

FIGURE 3 | Change in mean arterial pressure from baseline. Changes in mean arterial blood pressure (MAP) from baseline $(\mathrm{mmHg})$ during caesarean section with spinal anesthesia. Patients received either phenylephrine ( $n=12$; open circles) or ephedrine ( $n=12$; black circles).

of the NIRS value. It is possible that the $9 \%$ reduction in $\mathrm{ScO}_{2}$ following the administration of phenylephrine reflects contamination of the NIRS signal from extracranial tissue (Davie and Grocott, 2012).

There was no difference in fetal HR among groups of patients and neonatal outcome was similar, although there were small but probably clinically unimportant differences in regard to umbilical arterial lactate and venous base excess. Ephedrine could increase fetal HR due to $\beta$-adrenergic stimulation, when or if it crosses placenta inducing fetal acidaemia (LaPorta et al., 1995) The impact

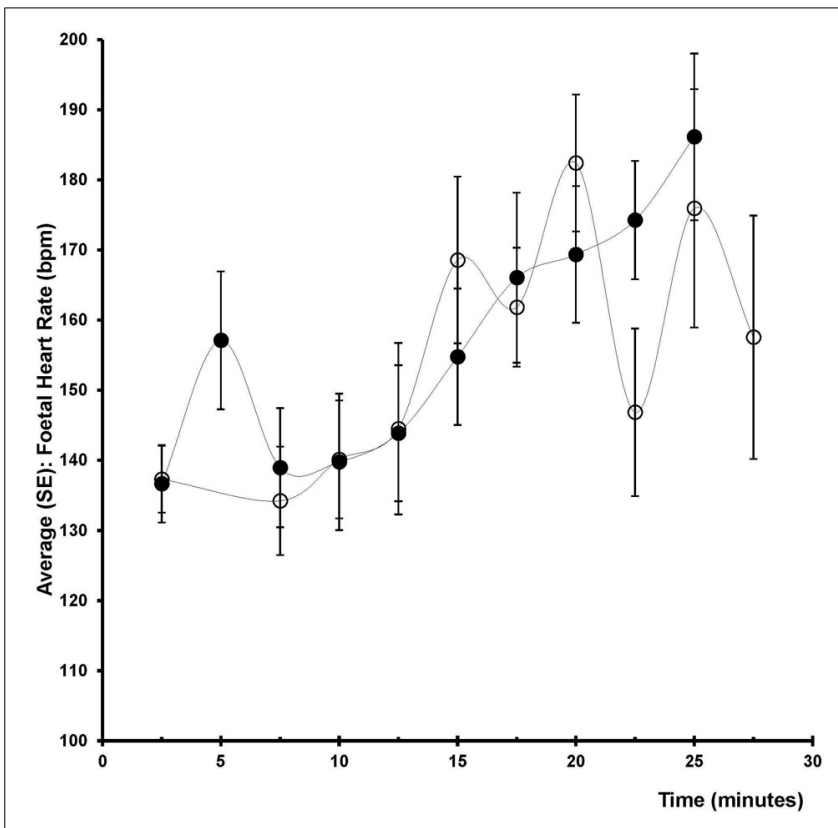

FIGURE 4 | Foetal heart rate. Change in fetal heart rate (bpm) after induction (2.5-5 min), before surgery ( $7.5-17.5 \mathrm{~min})$, after delivery (12.5-27.5 min) in two groups of 12 patients undergoing spinal anesthesia for caesarean section and receiving either phenylephrine (open circles) or ephedrine (black circles).

of ephedrine on arterial lactate and venous base excess could be related to an effect on uteroplacental or feto-placental circulation (McGrath et al., 1994; LaPorta et al., 1995).

We recognize that this evaluation is not a blinded randomized controlled trial and further that it is a limitation to the study that both physicians and nurses expected that ephedrine would increase maternal heart rate and therefore potentially influenced by that expectation. We estimated blood pressure $2.5 \mathrm{~min}$ after initiation of anesthesia and with the use of vasopressor this considered as a long time and could represent a limitation of the study.

There were some difficulties in using Nexfin to estimate cardiovascular variables during caesarean section when the patients moved due to anxiety. Also, Modelflow may not be provide an accurate CO (Remmen et al., 2002) and calibration by thermodilution (Jansen et al., 2001) or by the Fick method (van Lieshout et al., 2001) may be in need. However, for tracking changes in CO the Nexfin has been successfully validated against a thermodilution estimate during a deliberate reduction in central blood volume induced by standing up in healthy subjects (Harms et al., 1999) during cardiac surgery (Jansen et al., 2001) in intensive care medicine (Jellema et al., 1999) and during liver transplantation (Nissen et al., 2009c).

Phenylephrine preserved MAP and reduced HR and maintained CO with a slight increase in SV that was $5 \mathrm{ml}$ higher than the increase in the subjects receiving ephedrine. Phenylephrine may increase cardiac afterload to an extent that SV and CO decrease. On the other hand, an increase in vascular tone can increase venous return and thereby cardiac preload, SV and $\mathrm{CO}$ during hypovolemia as demonstrated in anesthetized pigs (Cannesson et al., 2012) Meng et al. found an increase in SV 
Table 3 | Umbilical cord blood analysis.

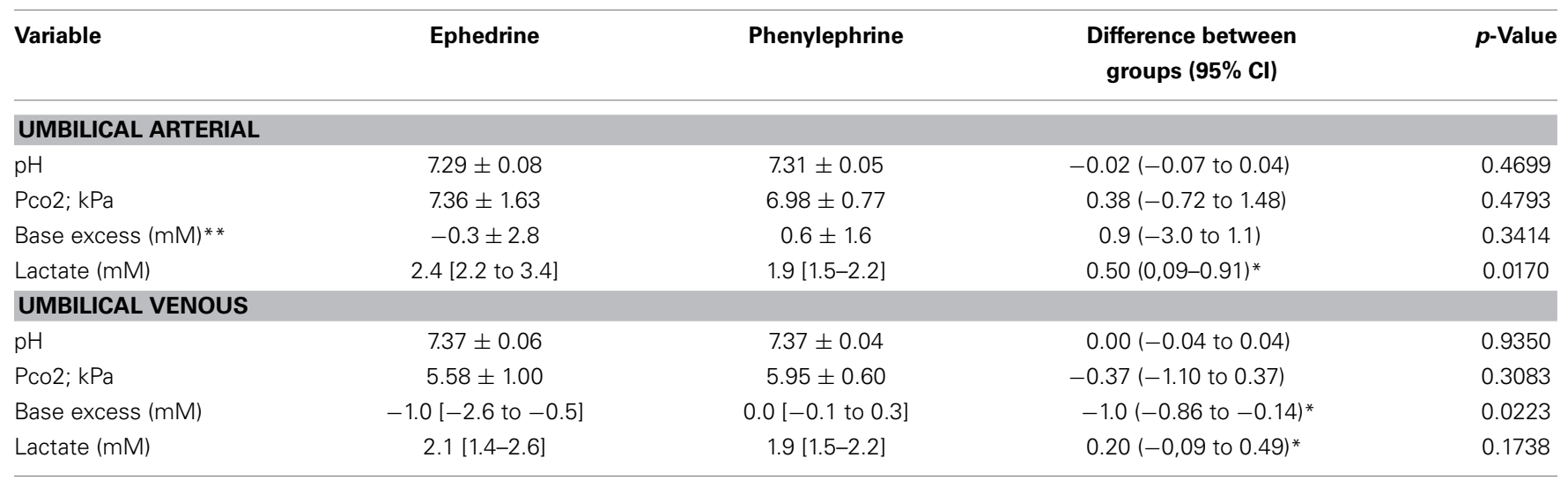

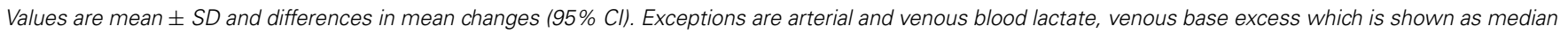
with interquartile range $(I Q R)$ in square brackets.

${ }^{*}$ Median difference.

Table 4 | Surgical times and intravenous fluid.

\begin{tabular}{lccc}
\hline Variable & Ephedrine & Phenylephrine & $\begin{array}{c}\text { Difference between } \\
\text { groups (95\% Cl) }\end{array}$ \\
\hline Induction to incision (min) & $13.3 \pm 3.3$ & $13.3 \pm 3.3$ & $0.0(-2.8$ to 2.8) \\
Induction to delivery (min) & $17.5 \pm 3.2$ & $17.3 \pm 3.9$ & $0.2(-2.8$ to 3.2$)$ \\
Total intravenous fluid (ml) & $904 \pm 254$ & $967 \pm 206$ & $-63(-259$ to 134)
\end{tabular}

Values are mean $\pm S D$ and differences in mean changes $(95 \% \mathrm{Cl}$ ).

and $\mathrm{CO}$ after administration of phenylephrine using pulsewave analysis by Vigileo-FloTrac in non-pregnant patients, but the increases were not confirmed with the use of a trans-esophageal Doppler apparatus (Meng et al., 2011b). Also an increase in SV in response to administration of phenylephrine is supported by Doherty et al. who used a CO monitor based on bi-reactance technology (Doherty et al., 2012) and by Dyer et al. using a LiDCOplus monitor (Dyer et al., 2009).

Another limitation of this trial was that we measured $\mathrm{ScO}_{2}$ and not cerebral blood flow, but parallel variation between middle cerebral artery mean flow velocity in basal cerebral arteries and $\mathrm{ScO}_{2}$ is reported (Ide et al., 1999; Yoshitani et al., 2007; Steiner et al., 2009) Furthermore, determination of internal jugular venous oxygen saturation could validate if the data obtained by NIRS are representative for the whole brain (Kim et al., 2000).

Three different NIRS approaches can be implemented: (1) Continuous wave (CW), (2) Frequency-domain (FD), and (3) time domain technology (TD). An approximate 3-4\% decrease in $\mathrm{ScO}_{2}$ is reported after treatment with phenylephrine with the use of FD (Meng et al., 2011a), compared with the 9\% decrease in this evaluation while others (Nissen et al., 2010; Ogoh et al., 2011) find an approximate decrease by $14 \%$ using CW. With commercial CW monitors there is a variation in the ability to estimate $\mathrm{ScO}_{2}$ (Davie and Grocott, 2012).

\section{CONCLUSION}

This study confirmed that infusion of phenylephrine and ephedrine are equally effective for sustaining blood pressure during elective caesarean section with spinal anesthesia. Phenylephrine, however, reduced $\mathrm{ScO}_{2}$ and maternal heart rate when compared to ephedrine but the two drugs induced an equal increase in fetal heart rate.

\section{AUTHOR'S CONTRIBUTION}

Peter Nissen, Niels H. Secher, Henning B. Nielsen, Kim Z. Rokamp, and Visti T. Foss conceived and designed the trial protocol. Visti T. Foss procured the project funding in cooperation with Department of Anaesthesia, Næstved Hospital, Denmark. Visti T. Foss and Kim Z. Rokamp contributed to clinical screening and recruitment of patients. Visti T. Fossand Kim Z. Rokamp handled the cooperation with the Good Clinical Practice (GCP) unit at the University of Copenhagen with VF as primary investigator and Kim Z. Rokamp as sponsor. Visti T. Foss and Robin Christensen did the statistical analyses. Visti T. Foss, Robin Christensen, Niels H. Secher and Kim Z. Rokamp drafted the manuscript, and Peter Nissen and Henning B. Nielsen contributed to the manuscript. All authors read and approved the final manuscript. Visti T. Foss and Kim Z. Rokamp accept full responsibility for this work and act as guarantors for the study.

\section{ACKNOWLEDGMENTS}

The authors wish to thank Malene L. Pedersen M.D. for the recruitment of patients. In addition the authors thank the midwives of Næstved Hospital, Denmark for their assistance and cooperation. For the use of INVOS 3100 cerebral oxymeter we 
thank Malene Brorsen, Covidien, Denmark. For proofreading the manuscript, we thank James Fisher, School of Sport and Exercise Sciences, University of Birmingham, UK.

\section{FUNDING}

This work was supported by Department of Anaesthesia, Næstved Hospital, Denmark and by the Copenhagen Muscle Research Center. The Musculoskeletal Statistics Unit, The Parker Institute, is supported by the Oak Foundation. The Rigshospitalet research foundation supported Henning B. Nielsen.

\section{REFERENCES}

Berlac, P. A., and Rasmussen, Y. H. (2005). Per-operative cerebral near-infrared spectroscopy (NIRS) predicts maternal hypotension during elective caesarean delivery in spinal anaesthesia. Int. J. Obstet. Anesth. 14, 26-31. doi: 10.1016/j.ijoa.2004.06.003

Bogert, L. W., and van Lieshout, J. J. (2005). Non-invasive pulsatile arterial pressure and stroke volume changes from the human finger. Exp. Physiol. 90, 437-446. doi: 10.1113/expphysiol.2005.030262

Cannesson, M., Zhongping, J., Chen, G., Vu, T. Q., and Hatib, F. (2012). Effects of phenylephrine on cardiac output and venous return depend on the position of the heart on the Frank-Starling relationship. J. Appl. Physiol. 113, 281-289. doi: 10.1152/japplphysiol.00126.2012

Choi, J., Wolf, M., Toronov, V., Wolf, U., Polzonetti, C., Hueber, D., et al. (2004). Noninvasive determination of the optical properties of adult brain: near-infrared spectroscopy approach. J. Biomed. Opt. 9, 221-229. doi: $10.1117 / 1.1628242$

Cyna, A. M., Andrew, M., Emmett, R. S., Middleton, P., and Simmons, S. W. (2006). Techniques for preventing hypotension during spinal anaesthesia for caesarean section. Cochrane Database Syst. Rev. 4:CD002251. doi: 10.1002/14651858.CD002 251.pub2

Das, S., Mukhopadhyay, S., Mandal, M., Mandal, S., and Basu, S. R. (2011). A comparative study of infusions of phenylephrine, ephedrine and phenylephrine plus ephedrine on maternal haemodynamics in elective caesarean section. Indian J. Anaesth. 55, 578-583. doi: 10.4103/0019-5049.90612

Davie, S. N., and Grocott, H. P. (2012). Impact of extracranial contamination on regional cerebral oxygen saturation: a comparison of three cerebral oximetry technologies. Anesthesiology 116, 834-840. doi: 10.1097/ALN.0b013e31824c00d7

Doherty, A., Ohashi, Y., Downey, K., and Carvalho, J. C. (2012). Phenylephrine infusion versus bolus regimens during cesarean delivery under spinal anesthesia: a double-blind randomized clinical trial to assess hemodynamic changes. Anesth. Analg. 115, 1343-1350. doi: 10.1213/ANE.0b013e31826ac3db

Dyer, R. A., Reed, A. R., van Dyk, D., Arcache, M. J., Hodges, O., Lombard, C. J., et al. (2009). Hemodynamic effects of ephedrine, phenylephrine, and the coadministration of phenylephrine with oxytocin during spinal anesthesia for elective cesarean delivery. Anesthesiology 111, 753-765. doi: 10.1097/ALN.0b013e3181b437e0

Harms, M. P., Wesseling, K. H., Pott, F., Jenstrup, M., Van Goudoever, J., Secher, N. H., et al. (1999). Continuous stroke volume monitoring by modelling flow from non-invasive measurement of arterial pressure in humans under orthostatic stress. Clin. Sci. 97, 291-301. doi: 10.1042/CS19990061

Hunt, K., Tachtsidis, I., Bleasdale-Barr, K., Elwell, C., Mathias, C., and Smith, M. (2006). Changes in cerebral oxygenation and haemodynamics during postural blood pressure changes in patients with autonomic failure. Physiol. Meas. 27, 777-785. doi: 10.1088/0967-3334/27/9/002

Ide, K., Horn, A., and Secher, N. H. (1999). Cerebral metabolic response to submaximal exercise. J. Appl. Physiol. 87, 1604-1608.

Jansen, J. R., Schreuder, J. J., Mulier, J. P., Smith, N. T., Settels, J. J., and Wesseling, K. H. (2001). A comparison of cardiac output derived from the arterial pressure wave against thermodilution in cardiac surgery patients. Br J Anaesth. 87, 212-222. doi: 10.1093/bja/87.2.212

Jellema, W. T., Wesseling, K. H., Groeneveld, A. B., Stoutenbeek, C. P., Thijs, L. G., and van Lieshout J. J. (1999). Continuous cardiac output in septic shock by simulating a model of the aortic input impedance: a comparison with bolus injection thermodilution. Anesthesiology 90, 1317-1328. doi: 10.1097/00000542-199905000-00016
Kim, M. B., Ward, D. S., Cartwright, C. R., Kolano, J., Chlebowski, S., and Henson, L. C. (2000). Estimation of jugular venous $\mathrm{O} 2$ saturation from cerebral oximetry or arterial $\mathrm{O} 2$ saturation during isocapnic hypoxia. J. Clin. Monit. Comput. 16, 191-199. doi: 10.1023/A:1009940031063

Kurihara, K., Kikukawa, A., Kobayashi, A., and Nakadate, T. (2007). Frontal cortical oxygenation changes during gravity-induced loss of consciousness in humans: a near-infrared spatially resolved spectroscopic study. J. Appl. Physiol. 103, 1326-1331. doi: 10.1152/japplphysiol.01191.2006

Langesaeter, E., Rosseland, L. A., and Stubhaug, A. (2008). Continuous invasive blood pressure and cardiac output monitoring during cesarean delivery: a randomized, double-blind comparison of low-dose versus high-dose spinal anesthesia with intravenous phenylephrine or placebo infusion. Anesthesiology 109, 856-863. doi: 10.1097/ALN.0b013e31818a401f

LaPorta, R. F., Arthur, G. R., and Datta, S. (1995). Phenylephrine in treating maternal hypotension due to spinal anaesthesia for caesarean delivery: effects on neonatal catecholamine concentrations, acid base status and Apgar scores. Acta Anaesthesiol. Scand. 39, 901-915. doi: 10.1111/j.1399-6576.1995. tb04195.x

Littell, R. C., Pendergast, J., and Natarajan, R. (2000). Modelling covariance structure in the analysis of repeated measures data. Stat. Med. 19, 1793-1819. doi: 10.1002/1097-0258(20000715)19:13<1793::AID-SIM482>3.3.CO;2-H

Lucas, S. J., Tzeng, Y. C., Galvin, S. D., Thomas, K. N., Ogoh, S., and Ainslie, P. N. (2010). Influence of changes in blood pressure on cerebral perfusion and oxygenation. Hypertension 55, 698-705. doi: 10.1161/HYPERTENSIONAHA.109.146290

Madsen, P., Olsen, S. B., Nielsen, H. B., Burcev, I., and Secher, N. H. (1998). Nearinfrared spectrophotometry determined brain oxygenation during fainting. Acta Physiol. Scand. 162, 501-517. doi: 10.1046/j.1365-201X.1998.0308f.x

McGrath, J. M., Chestnut, D. H., Vincent, R. D., DeBruyn, C. S., Atkins, B. L., and Poduska, D. J. (1994). Ephedrine remains the vasopressor of choice for treatment of hypotension during ritodrine infusion and epidural anesthesia. Anesthesiology 80, 1073-1081. doi: 10.1097/00000542-199405000-00016

Meng, L., Cannesson, M., Alexander, B. S., Yu, Z., Kain, Z. N., Cerussi, A. E., et al. (2011a). Effects of phenylephrine and ephedrine bolus treatment on cerebral oxygenation in anaesthetized patients. Br. J. Anaesth. 107, 209-217. doi: $10.1093 / \mathrm{bja} / \mathrm{aer} 150$

Meng, L., Gelb, A. W., and McDonagh, D. L. (2013). Changes in cerebral tissue oxygen saturation during anaesthetic-induced hypotension: an interpretation based on neurovascular coupling and cerebral autoregulation. Anaesthesia 68, 736-441. doi: 10.1111/anae.12254

Meng, L., Tran, N. P., Alexander, B. S., Laning, K., Chen, G., Kain, Z. N., et al. (2011b). The impact of phenylephrine, ephedrine, and increased preload on third-generation Vigileo-FloTrac and esophageal doppler cardiac output measurements. Anesth. Analg. 113, 751-757. doi: 10.1213/ANE.0b013e31822649fb

Mercier, F. J., Riley, E. T., Frederickson, W. L., Roger-Christoph, S., Benhamou, D., and Cohen, S. E. (2001). Phenylephrine added to prophylactic ephedrine infusion during spinal anesthesia for elective cesarean section. Anesthesiology 95, 668-674. doi: 10.1097/00000542-200109000-00020

Ngan Kee, W. D., Khaw, K. S., Lau, T. K., Ng, F. F., Chui, K., and Ng, K. L. (2008a). Randomised double-blinded comparison of phenylephrine vs ephedrine for maintaining blood pressure during spinal anaesthesia for non-elective caesarean section. Anaesthesia 63, 1319-1326. doi: 10.1111/j.1365-2044.2008.05635.x

Ngan Kee, W. D., Lee, A., Khaw, K. S., Ng, F. F., Karmakar, M. K., and Gin, T. (2008b). A randomized double-blinded comparison of phenylephrine and ephedrine infusion combinations to maintain blood pressure during spinal anesthesia for cesarean delivery: the effects on fetal acidbase status and hemodynamic control. Anesth. Analg. 107, 1295-1302. doi: 10.1213/ane.0b013e31818065bc

Nissen, P., Brassard, P., Jørgensen, T. B., and Secher, N. H. (2010). Phenylephrine but not ephedrine reduces frontal lobe oxygenation following anesthesiainduced hypotension. Neurocrit. Care 12, 17-23. doi: 10.1007/s12028-0099313-x

Nissen, P., Nielsen, H. B., van Lieshout, J. J., and Secher, N. H. (2009a). Frontal lobe oxygenation is maintained during hypotension following propofol-phentanyl anesthesia. AANAJ. 77, 271-276.

Nissen, P., Pacino, H., Frederiksen, H. J., Novovic, S., and Secher, N. H. (2009b). Near-infrared spectroscopy for evaluation of cerebral autoregulation during orthotropic liver transplantation. Neurocrit. Care 11, 235-241. doi: $10.1007 / s 12028-009-9226-8$ 
Nissen, P., Van Lieshout, J. J., Novovic, S., Bundgaard-Nielsen, M., and Secher, N. H. (2009c). Techniques of cardiac output measurement during liver transplantation: arterial pulse wave versus thermodilution. Liver Transplant. 15, 287-291. doi: 10.1002/lt.21689

Ogoh, S., Sato, K., Fisher, J. P., Seifert, T., Overgaard, M., and Secher, N. H. (2011). The effect of phenylephrine on arterial and venous cerebral blood flow in healthy subjects. Clin. Physiol. Funct. Imaging 31, 445-451. doi: 10.1111/j.1475097X.2011.01040.x

Paulson, O. B., Strandgaard, S., and Edvinsson, L. (1990). Cerebral autoregulation. Cerebrovasc. Brain Metab. Rev. 2, 161-192.

Remmen, J. J., Aengevaeren, W. R., Verheugt, F. W., van ver Werf, T., Luijten, H. E., Bos, A., et al. (2002). Finapres arterial pulse wave analysis with model flow is not a reliable non-invasive method for assessment of cardiac output. Clin. Sci. 103, 143-149. doi: 10.1042/CS20010357

Saravanan, S., Kocarev, M., Wilson, R. C., Watkins, E., Columb, M. O., and Lyons, G. (2006). Equivalent dose of ephedrine and phenylephrine in the prevention of post-spinal hypotension in Caesarean section. Br. J. Anaesth. 96, 95-99. doi: 10.1093/bja/aei265

Schulz, K. F., Altman, D. G., and Moher, D. (2010). for the CONSORT Group. CONSORT 2010 Statement: updated guidelines for reporting parallel group randomised trials. J. Clin. Epi. 63, 834-840. doi: 10.1016/j.jclinepi.2010.02.005

Steiner, L. A., Pfister, D., Strebel, S. P., Radolovich, D., Smielewski, P., and Czosnyka, M. (2009). Near-infrared spectroscopy can monitor dynamic cerebral autoregulation in adults. Neurocrit. Care 10, 122-128. doi: 10.1007/s12028-008-9140-5

Suzuki, K., Asahina, M., Suzuki, A., and Hattori, T. (2008). Cerebral oxygenation monitoring for detecting critical cerebral hypoperfusion in patients with multiple system atrophy during the head-up tilt test. Intern. Med. 47, 1681-1687. doi: 10.2169/internalmedicine.47.1094

Tan, C. O. (2012). Defining the characteristic relationship between arterial pressure and cerebral flow. J. Appl. Physiol. 15, 1194-1200. doi: 10.1152/japplphysiol.00783.2012

van Lieshout, J. J., Pott, F., Madsen, P. L., van Goudoever, J., and Secher, N. H. (2001). Muscle tensing during standing: effects on cerebral tissue oxygenation and cerebral artery blood velocity. Stroke 32, 1546-1551. doi: 10.1161/01.STR.32.7.1546

Vesser, M., Hofmann, T., Roth, R., Klöhr, S., Rossaint, R., and Hessen, M. (2012). Vasopressors for management of hypotension after spinal anesthesia for elective caesarean section. Systematic review and cumulative meta-analysis. Acta Anaesthesiol. Scand. 56, 810-816. doi: 10.1111/j.1399-6576.2011.02646.x

Wang, M., Han, C. B., and Qian, Y. N. (2011). Comparison of effects in puerpera and fetus with ephedrine and phenylephrine during a cesarean delivery. J. Chin. Med. Assoc. 91, 2195-2198.

Yoshitani, K., Kawaguchi, M., Miura, N., Okuno, T., Kanoda, T., Ohnishi, Y., et al. (2007). Effects of hemoglobin concentration, skull thickness, and the area of the cerebrospinal fluid layer on near-infrared spectroscopy measurements. Anesthesiology 106, 458-462. doi: 10.1097/00000542-200703000-00009

Conflict of Interest Statement: The authors declare that the research was conducted in the absence of any commercial or financial relationships that could be construed as a potential conflict of interest.

Received: 22 November 2013; accepted: 08 February 2014; published online: 03 March 2014.

Citation: Foss VT, Christensen R, Rokamp KZ, Nissen P, Secher NH and Nielsen HB (2014) Effect of phenylephrine vs. ephedrine on frontal lobe oxygenation during caesarean section with spinal anesthesia: an open label randomized controlled trial. Front. Physiol. 5:81. doi: 10.3389/fphys.2014.00081

This article was submitted to Integrative Physiology, a section of the journal Frontiers in Physiology.

Copyright (C) 2014 Foss, Christensen, Rokamp, Nissen, Secher and Nielsen. This is an open-access article distributed under the terms of the Creative Commons Attribution License (CC BY). The use, distribution or reproduction in other forums is permitted, provided the original author(s) or licensor are credited and that the original publication in this journal is cited, in accordance with accepted academic practice. No use, distribution or reproduction is permitted which does not comply with these terms. 